\title{
Consequences of Lockdown During COVID-19 Pandemic in Lifestyle and Emotional State of Children in Argentina
}

\author{
María Victoria Fasano ${ }^{1,2}$, Marcela Padula ${ }^{1}$, María Ángeles Azrak ${ }^{1}$, Ana Julia Avico ${ }^{1}$, \\ Marisa Sala ${ }^{1}$ and María F. Andreoli ${ }^{1,3 *}$ \\ ${ }^{1}$ Instituto de Desarrollo e Investigaciones Pediátricas, Hospital de Niños de La Plata - Comisión de Investigaciones \\ Científicas-Provincia de Buenos Aires, Buenos Aires, Argentina, ${ }^{2}$ Centro de Matemática La Plata, Facultad de Ciencias \\ Exactas, Universidad Nacional de La Plata, Buenos Aires, Argentina, ${ }^{3}$ Consejo Nacional de Investigaciones Científicas y \\ Técnicas, Buenos Aires, Argentina
}

OPEN ACCESS

Edited by:

Soly I. Erlandsson

University West, Sweden

Reviewed by:

Serena Di Giandomenico, University of Urbino Carlo Bo, Italy Paolo Roma

Sapienza University of Rome, Italy

*Correspondence: María F. Andreol

mfandreoli@fbcb.unl.edu.ar

Specialty section

This article was submitted to Child and Adolescent Psychiatry,

a section of the journal

Frontiers in Pediatrics

Received: 28 January 2021

Accepted: 15 June 2021

Published: 14 July 2021

Citation:

Fasano MV, Padula M, Azrak MÁ Avico AJ, Sala M and Andreoli MF (2021) Consequences of Lockdown

During COVID-19 Pandemic in

Lifestyle and Emotional State of

Children in Argentina.

Front. Pediatr. 9:660033.

doi: 10.3389/fped.2021.660033
The implications of the coronavirus disease (COVID-19) lockdown measurements and social isolation in children and their parents are still unknown. The aims of this study were to examine the impact of COVID-19 lockdown on emotional state, feelings and lifestyle of children and their parents, to explore the association between parental characteristics and child well-being and to examine whether the impact of lockdown depends on socio-economic status. Parents completed an online survey including data about socio-demographic information, parent and child feelings and lifestyle during lockdown. Logistic regression and correlation analysis were used to establish associations between variables. In total, 814 parents with children between 4 and 11 were included in the study. According to parents, $69.5 \%$ of the children showed changes in their emotional state, $55.3 \%$ altered their routine and $62.6 \%$ showed sleep disorders. Families with lower socio-economic status were more worried about health, shortage of food and household income $(p<0.01)$. Parent and children concern about food/essential items were highly associated [OR (Cl 95\%) 13.0 (6.81, 26.5), $p<0.01]$. Adverse children's emotional state was associated with parental feeling of loneliness $(r=0.35)$ and inversely associated with keeping a routine $(r=-0.11)$. Sleep changes were inversely associated with keeping a routine and having a balcony/garden ( $r=-0.53$ and -0.16$)$. We conclude that lockdown affected emotional state and lifestyle of children and parents, which were strongly related. Routine and positive parental attitude supported children's well-being. Economic issues were an important concern in families with lower socio-economic status. Our findings can help to promote child health during lockdown.

Keywords: COVID-19, pandemic, lockdown, children, emotional state

\section{INTRODUCTION}

The health, social and economic implications of the coronavirus disease 2019 (COVID-19) pandemic are still difficult to estimate. To contain and mitigate the spread of COVID-19, in March 2020 the Argentinean Government decided for strong lockdown measurements such as the cessation of school programs for children who consequently needed to remain at home. Although 
some restrictions started to ease over time, by November 2020 most of the schools still remained closed (1).

COVID-19 pandemic and lockdown measurements led to social isolation that affected severely the mental health of the general population all over the world, causing an increase in mental distress (2), depression and anxiety through the lockdown (3-7), sometimes associated with changes in feelings and lifestyle that include reduced physical activity, unhealthy eating habits, inadequate sleep quality and feeling of loneliness $(2,4,7,8)$. Family lifestyle was also drastically affected: parents suffered psychological distress due to unstable financial circumstances, school closures, and suspended educational services $(9,10)$. Children and adolescents also started to experience adverse emotional responses (stress, worry, helplessness, social and risky behavioral problems, anxiety, and depression) (11-16) and changes in lifestyle such as sleeping problems, increased screen exposure, reduced physical activity and unhealthy eating habits (17-20).

The lockdown measurements affected household finances with stronger implications for families with children living in poverty and/or crowded housing conditions (21-23). In the first half of 2020 Argentina's poverty rate rose to $40.9 \%$, as reported by the country's official INDEC statistics agency (24), underscoring the devastating impact of the pandemic on the country's population. The lockdown presumably affected to a different extent people from different socio-economic status, and precise estimation of such impact is extremely valuable to decide future Government measures to address the consequences of the unprecedented crisis.

As mentioned above, several studies reported the effects of pandemic lockdown in adults $(3,4,8,25)$ and children $(18,19$, 26-29) mainly in Asia and Europe, to our knowledge only one of these studies was conducted in toddlers and pre-schoolers from Latin America (26). In addition, few studies focused on parentchild dyads $(10,21,22,30)$. Thus, this study aimed to examine the impact of COVID-19 pandemic lockdown on emotional state, feelings and lifestyle of children and their parents in Argentina, focusing on their emotions, emotional stability, worries, routine, sleep, and daily activities. Also, the study explored the association between parental feelings and worries and child well-being. Furthermore, the study examined whether the impact of social isolation during the pandemics depends on the socio-economic status of the family.

\section{MATERIALS AND METHODS}

\section{Sample Selection}

Parents filled out an anonymous online survey, after reading the written consent form and explicitly agreeing to take part of the study. The survey was conducted from May 26th to June 17th 2020 , targeting parents of children aged 4-11 years-old. This age range was chosen to include children receiving pre-school and primary education. In case of multiple children, parents were asked to report on one child only. All questions were answered by the parent. The survey was conducted using an online platform, accessible through any device with an Internet connection. The survey was disseminated through institutional and private social networks (Twitter, Facebook, and Instagram), and institutional mailing lists. This method of administration provides a sample whose population parameters cannot be controlled as it is the case for probabilistic sampling. Such strategy was effective for the research objectives, because it facilitated the wide dissemination of the survey during a period with territorial restrictions due to the pandemic. The final sample included 814 families because respondents with missing or implausible data $(n=302$, e.g., child age out of range) were excluded from the analyses. Inclusion criteria: adult ( $>18$ years old) mothers and fathers with children 4-11 years-old. Exclusion criteria: adults who did not have children or whose children were out of the age range.

\section{Survey}

The survey was specifically built using Google Form by the Institute of Development and Paediatric Research (IDIP), La Plata's Children Hospital, Buenos Aires, Argentina. For this, scientific literature related to the impact of lockdown on emotional state, feelings and lifestyle was reviewed $(3,4,8$, $12,18,28)$ and questionnaires applied in previous studies were considered for creating our survey. The survey was first tested in a small number of parents who were asked whether the questions were clear. The survey (Supplementary Table 1) included 43 closed questions, for each a list of acceptable responses was provided. Questions were divided into three different sections: (1) parent and family socio-demographic data (age, educational level, hometown, employment, telework, public health assistance, social welfare benefits, number of rooms in the house, number of persons living in the house, having a balcony/garden in the house, presence of pets), (2) children's data, feelings and lifestyle during lockdown (gender, age, worries about COVID-19, feelings and worries during lockdown, emotional state, routine, time spent in different activities, sleep, virtual contact with family/friends), (3) parent's feelings and worries during lockdown (worries about COVID-19 and feelings and worries during lockdown).

\section{Statistical Analyses}

Statistical analyses were performed using the $\mathrm{R}$ software version 3.6.0. Quantitative variables are presented as median (interquartile range, IQR) and categorical data are summarized as frequency counts and percentages. Chi-squared test or Fisher's exact test were used to test for associations between categorical variables. Pairwise comparisons between multiple groups were adjusted by the Benjamini and Hochberg $(\mathrm{BH})$ method (31). Logistic regression models were used to estimate the odds ratio (OR) and 95\% confidence interval (CI) between children's and parent's feelings and worries. Associations between children's emotional state, sleep and daily activities and parent's feelings and socio-demographic factors were assessed by polyserial or polychoric correlations according to the nature of the variables. To identify possible socioeconomic status (SES) subgroups, we conducted a cluster analysis on the educational levels of parents, social welfare benefits, public health assistance, number of rooms in the house and number of persons living in the household. All statistical tests were two tailed/bilateral, and the significance level was set at $p<0.01$. 


\section{Ethics Approval}

The study was approved by the Institutional Committee for the Revision of Research Protocols (CIRPI) of the Institute of Development and Paediatric Research (IDIP), La Plata Children's Hospital, and conducted according to the Declaration of Helsinki guidelines and Argentinian legal provisions governing clinical research on humans. We obtained informed consent from the participants included in this study.

\section{RESULTS}

\section{Family Features and Clustering Based on the Socio-Economic Status (SES)}

Respondents were between 21 and 56 years-old (median: 39), primarily college or university students/graduates $(87.17 \%)$, employees $(62.9 \%)$ that during lockdown were working parttime $(42.8 \%)$ and from home (68.9\%). More than $13 \%$ reported receiving social welfare benefits and $12.3 \%$ were assisted in the public health system. Home residences predominantly had 23 rooms and $88.8 \%$ housed between 3 and 5 people. Based on this, the median for the ratio between the number of persons living in the household and the number of rooms in the house was 1.5. Children were uniformly distributed by gender and age (Supplementary Table 2). To assess if the impact of the lockdown depended on SES, we generated a 2-group partitioning of the families by conducting a cluster analysis including the following categorical variables: (1) public health assistance, (2) employment, (3) education, (4) reception of social welfare benefits, and (5) ratio between the number of persons living in the household and the number of rooms in the house (above or below 1.5). As a result, 378 parents (46.4\%) were attributed to a high SES cluster, which included parents with high educational levels (university), low reception of social welfare benefits, low use of public health assistance and a number of persons living in the household/number of rooms in the house ratio $<1.5$, while 436 parents $(53.6 \%)$ were attributed to a low SES cluster.

\section{Impact of COVID-19 Pandemic Lockdown on Children \\ Emotional State}

According to their parents, $69.5 \%$ of the children showed changes in their emotional state. More than half of the children had adverse consequences on their emotional state: $46.1 \%$ of the parents reported mood instability in their children, $4.1 \%$ reported a nervous or aggressive mood and $3.8 \%$ sadness or crying. On the other hand, $10.7 \%$ of the children were happy during lockdown. Also $4.8 \%$ of the parents reported another type of emotional change in their children. The percentage of children who were happier under lockdown was higher between 4 and 6 yearsold (14.4\%) than children between 9 and 11 (7.4\%, $p<0.001)$ (Supplementary Figure 1). The percentage of children with no changes in their emotional state was higher between 9 and 11 $(41 \%, p<0.001)$. No differences were observed between the low and high SES clusters $(p=0.574)$ or between boys and girls $(p=0.039)$.

\section{Feelings}

Feelings of children during lockdown are shown in Table 1. According to the parent's opinion, $27 \%$ of the children were worried about getting/transmitting the COVID-19, older children (9-11 years old) being more worried than younger children. More than $16 \%$ were afraid to leave the house. Most of the children missed visiting their relatives (90.4\%) and attending to school (64.6\%), independently of their age but more often among girls than boys (93.6 vs. $87.2 \%, p=0.002$ and 71.2 vs. $57.3 \%, p<0.001$, respectively). Children mainly between 6 and 7 years-old missed practicing sports $(75.9 \%, p<0.001)$ and their friends $(89.1 \%, p=0.002)$, with no significant gender differences. Regarding SES, children belonging to families in the low cluster were more worried about food or money shortage than children in the high SES cluster.

\section{Lifestyle Changes}

As shown in Table 1, 55.3\% of the parents reported that their children altered their routine during lockdown, independently of their age. Around $62 \%$ showed sleep disorders, mainly going to sleep at late hours, and this percentage increased with age. Girls showed more sleep disorders than boys (67 vs. $56.7 \%, p=0.004$ ). Most of the children communicated with their friends/family outside of the household at least once a day via WhatsApp $(65.5 \%)$, social media $(32.2 \%)$, or online gaming $(38.1 \%)$, and this percentage increased with age. Social media was used by $14.1 \%$ of the children and $19.5 \%$ played online games constantly or on-and-off throughout the day, especially boys $(p<0.001$ vs. girls). SES did not affect routine, sleep or virtual contact with friends/family.

\section{Daily Activities}

As shown in Table 2, 31.8\% of the children spent $<30$ $\mathrm{min}$ /day being outside, and $36.2 \%$ spent $<30 \mathrm{~min}$ doing physical activity (inside or outside), without gender differences. Concerning indoor activities, $57.7 \%$ of the children spent $2 \mathrm{~h}$ or more playing inside and $36.2 \%$ spent $<30$ min doing handicrafts. Most of the children (62.4\%) spent $<30 \mathrm{~min}$ a day reading. Regarding screen time, $28.1 \%$ spent more than $2 \mathrm{~h}$ playing screen games and $33.9 \%$ spent more than $2 \mathrm{~h}$ watching videos and/or TV. Also $21.6 \%$ spent more than $2 \mathrm{~h}$ playing screen games plus more than $2 \mathrm{~h}$ watching videos and/or TV.

Children spent time in different activities depending on their age and gender. Younger children (4-6 years-old) spent less time doing school homework than older children. Besides, younger children spent more time outside, doing physical activity, playing, doing handicrafts and reading than older children (911 years-old). On the other hand, older children spent more time playing screen games. Significant gender differences were observed in screen games and handicrafts: boys spent more time playing screen games $(36.1 \%$ spent more than 2 h/day vs. $22.2 \%$ in girls, $p<0.001$ ) and girls spent more time doing handicrafts (73.3\% spent more than $30 \mathrm{~min} /$ day vs. $53.3 \%$ in boys, $p<0.001$ ). Time spent in different activities was not affected by SES. 
TABLE 1 | Children's feelings and lifestyle during lockdown [n (\%)].

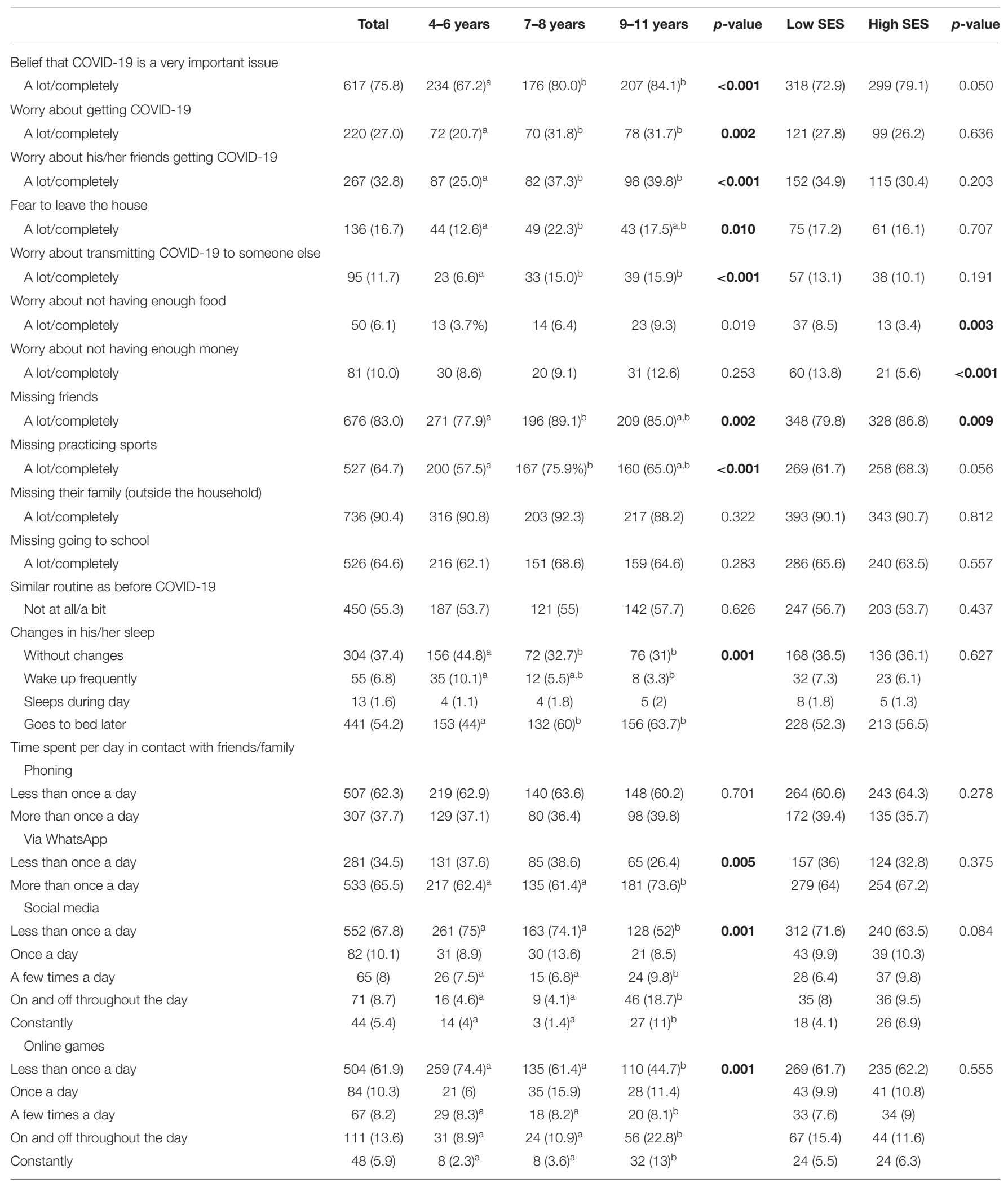

Data are presented as frequency counts and percentages. Values in bold indicate statistically significant difference $(p<0.01)$. a,b Post-hoc comparisons using BH method, different letters indicate significant differences at level 0.01 between age groups. 
TABLE 2 | Time spent in different activities during lockdown [n (\%)].

\begin{tabular}{|c|c|c|c|c|c|c|c|c|}
\hline & Total & 4-6 years & $7-8$ years & $9-11$ years & $p$-value & Low SES & High SES & $p$-value \\
\hline \multicolumn{9}{|l|}{ Time spent outside } \\
\hline Less than $30 \mathrm{~min}$ & $259(31.8)$ & $91(26.1)^{\mathrm{a}}$ & $70(31.8)^{a, b}$ & $98(39.8)^{b}$ & 0.002 & $136(31.2)$ & $123(32.5)$ & 0.706 \\
\hline \multicolumn{9}{|c|}{ Physical activity (outside or inside) } \\
\hline Less than $30 \mathrm{~min}$ & $295(36.2)$ & $93(26.7)^{\mathrm{a}}$ & $78(35.5)^{\mathrm{a}}$ & $124(50.4)^{b}$ & $<0.001$ & $156(35.8)$ & $139(36.8)$ & 0.771 \\
\hline \multicolumn{9}{|l|}{ Playing outside } \\
\hline $2 \mathrm{~h}$ or more & $470(57.7)$ & $243(69.8)^{a}$ & $132(60)^{\mathrm{a}}$ & $95(38.6)^{b}$ & $<0.001$ & $252(57.8)$ & $227(60.1)$ & 0.999 \\
\hline \multicolumn{9}{|c|}{ Time spent doing school homework } \\
\hline Less than $2 \mathrm{~h}$ & $358(44.0)$ & $203(58.3)^{a}$ & $83(37.7)^{\mathrm{b}}$ & $72(29.3)^{b}$ & $<0.001$ & $198(45.4)$ & $160(42.3)$ & 0.081 \\
\hline $2-4 h$ & $292(35.9)$ & $108(31)$ & $88(40.0)$ & $96(39)$ & & $163(37.4)$ & $129(34.1)$ & \\
\hline 5 or more hours & $164(20.1)$ & $37(10.6)^{\mathrm{a}}$ & $49(22.3)^{b}$ & $78(31.7)^{\mathrm{b}}$ & & $75(17.2)$ & 89 (23.5) & \\
\hline \multicolumn{9}{|c|}{ Doing craft/hand activities } \\
\hline \multicolumn{9}{|c|}{ Reading (alone or with someone) } \\
\hline Less than $30 \mathrm{~min}$ & $508(62.4)$ & $198(56.9)^{\mathrm{a}}$ & $136(61.8)^{a, b}$ & $174(70.7)^{b}$ & 0.003 & $255(58.5)$ & $253(66.9)$ & 0.014 \\
\hline \multicolumn{9}{|c|}{ Playing (video) games with cell phone, tablet or computer } \\
\hline $2 \mathrm{~h}$ or more & $229(28.1)$ & $68(19.5)^{\mathrm{a}}$ & $51(23.2)^{\mathrm{a}}$ & $110(44.7)^{b}$ & $<0.001$ & $118(27.1)$ & $111(29.4)$ & 0.482 \\
\hline \multicolumn{9}{|c|}{ Watching videos/movies/cartoons on a screen (cell phone, tablet, or TV) } \\
\hline $2 \mathrm{~h}$ or more & $276(33.9)$ & $112(32.2)$ & 68 (30.9) & $96(39.0)$ & 0.125 & $144(33.0)$ & $132(34.9)$ & 0.603 \\
\hline
\end{tabular}

Data are presented as frequency counts and percentages. Values in bold indicate statistically significant difference $(p<0.01) .{ }^{a, b, c}$ Post-hoc comparisons using BH method, different letters indicate significant differences at level 0.01 between age groups.

\section{Impact of COVID-19 Pandemic Lockdown on Families and Association to Children's Lifestyle and Emotional State} Parent's Feelings

Almost half (47.1\%) of the parents were worried about getting/transmitting COVID-19 and $27.9 \%$ were afraid to leave the house for essential activities such as work or essential shopping. Besides, 59.1\% reported being worried about their children's use of screen, and $68.4 \%$ found it stressful to keep children entertained during lockdown. Also, $16.6 \%$ of the parents felt lonely, $18.8 \%$ did not feel capable to help their child with school homework and $45.1 \%$ did not have time to play with their children. These worries and feelings were not affected by SES. In contrast, preoccupations about health (physical or mental), shortage of food/essential items, total household income and children's future were higher in families in the low SES cluster (Supplementary Table 3).

\section{Associations Between Child and Parent Feelings and Worries During Lockdown}

As shown in Table 3, parental fright to leave the house and concern about accessibility to food/essential items, household income and children's future were highly associated with similar worries in the children. Particularly, children whose parents were concerned about having enough food were more likely to be worried about food shortage during lockdown [OR (CI 95\%) 13.0 $(6.81,26.5)]$.
TABLE 3 | Odds ratio (Cl 95\%) between children's and parent's feelings and worries.

\begin{tabular}{|c|c|c|c|}
\hline & $\begin{array}{l}\text { Child afraid to } \\
\text { leave the house }\end{array}$ & $\begin{array}{l}\text { Child worried } \\
\text { about not having } \\
\text { enough food }\end{array}$ & $\begin{array}{l}\text { Child worried } \\
\text { about not having } \\
\text { enough money }\end{array}$ \\
\hline $\begin{array}{l}\text { Parental fear to leave } \\
\text { the house }\end{array}$ & $4.10(2.80,6.02)$ & $4.73(2.63,8.70)$ & $2.54(1.59,4.06)$ \\
\hline $\begin{array}{l}\text { Parental concern } \\
\text { about having enough } \\
\text { food or essential } \\
\text { items }\end{array}$ & $2.37(1.59,3.51)$ & $13.0(6.81,26.5)$ & $6.95(4.31,11.4)$ \\
\hline $\begin{array}{l}\text { Parental concern } \\
\text { about total household } \\
\text { income }\end{array}$ & $1.99(1.37,2.89)$ & $7.08(3.55,15.7)$ & $6.23(3.66,11.2)$ \\
\hline $\begin{array}{l}\text { Parental concern } \\
\text { about children's } \\
\text { future }\end{array}$ & $2.44(1.65,3.67)$ & $5.03(2.46,11.7)$ & $4.83(2.75,9.08)$ \\
\hline
\end{tabular}

Values in bold indicate statistical significance $(p<0.01)$.

\section{Associations Between Children's Emotional State, Sleep and Activities and Routine, Parent's Feelings, and Socio-Demographic Factors}

Only selected associations $(|r|>0.1, \quad p<0.01) \quad$ (32) were highlighted here. As shown in Table 4, parental age and part-time working were positively associated with time spent doing school homework. The presence of balcony/garden was inversely associated with changes in child's sleep and positively associated with the amount of time spent outside. Keeping 
TABLE 4 | Associations between children's emotional state, sleep and daily activities and routine, parent's feelings, and socio-demographic factors.

\begin{tabular}{|c|c|c|c|c|}
\hline & $\begin{array}{l}\text { Adverse emotional state } \\
\qquad(0=\text { No, } 1=\text { Yes })\end{array}$ & $\begin{array}{l}\text { Changes in sleep } \\
(0=\text { No, } 1=\text { Yes })\end{array}$ & Time spent outside & Time spent doing schoolwork \\
\hline Parent's age & -0.09 & 0.01 & -0.02 & 0.15 \\
\hline Parent's work (full or part-time) & -0.03 & -0.07 & 0.08 & 0.11 \\
\hline Having a balcony/garden ( $0=$ No, $1=$ Yes) & -0.07 & -0.16 & 0.30 & 0.07 \\
\hline Routine similar to before COVID-19 & -0.11 & -0.53 & 0.08 & 0.16 \\
\hline Parent feeling lonely & 0.35 & 0.22 & -0.04 & -0.07 \\
\hline Parent feeling capable to help child with schoolwork & -0.32 & -0.04 & 0.02 & 0.10 \\
\hline Parent with time to play with their child & -0.23 & -0.16 & -0.01 & -0.07 \\
\hline
\end{tabular}

Polyserial or polychoric correlations are shown, correlations in bold are statistically significant at level 0.01.

a routine similar to how things were before COVID-19 was inversely associated with adverse emotional state and with changes in sleep, and positively associated with the time spent doing school homework. The feeling of loneliness of parents was associated with adverse emotional state and sleep changes in children, while the feeling of being able to help with school homework was inversely associated with adverse emotional state. Having time to play with children was inversely associated with adverse emotional state and with changes in sleep. Time spent in physical activity, reading, playing videogames or watching a screen did not present association with routine, socio-demographic factors or parent's feelings (data not shown).

\section{DISCUSSION}

To our knowledge, this is the first study investigating how COVID-19 pandemic lockdown affects lifestyle and emotional state of children and the links between child and parent well-being in the context of pandemic-associated lockdown in families from Latin America. Our study found that the socio-economic status of the family, the alteration of the routine as a consequence of the pandemic, the parental feelings and the access to a balcony/garden strongly affect children's emotional state and lifestyle.

Current results indicate that $69.5 \%$ of the parents reported changes in the emotional state of their children after 2 months of lockdown. Younger children showed more dramatic mood changes. The most frequent feature was mood instability. Feelings of worry, fear and longing for their relatives and friends and school were also frequently reported by most parents. Younger children were also happier to staying at home, which may reflect their interest in spending more time with their parents/caregivers. No gender differences were observed, in agreement with other studies in children $(20,27)$, although some studies in adolescents show higher depression and anxiety levels in females (16). On the whole, our results are in line with the observations of other authors. In Italian children, a self-reported study (20) showed frequent mood swings in nearly half of the responders along with anxiety and depression symptoms. Other study in Spanish and Italian children reported that $85.7 \%$ of the parents perceived changes in their children's emotional state and behavior during lockdown, mainly difficulty concentrating and boredom (15). Studies in Chinese children show behavioral and emotional problems (17.6\%) (29) and anxiety and depression rates between $18 \%$ (27) and 24\% (12). Although our study did not assess depressive or anxiety symptoms, the observed changes in the emotional state could precede mental health decline and further evolve into such anxiety, depression, and posttraumatic stress symptoms.

Our study found important changes in the lifestyle of children, mainly loss of routine and changes in sleep. One of the most reported stressors of parents under pandemic lockdown was the disruption of children's routine (33), which can be detrimental because routines help children feel safe and contribute to healthy habits (33). In line with our results, other studies also reported changes in sleep. Sleep time increased in Canadian and Spanish children $(17,18)$, and behavioral health was impaired in American children (22). Other authors (20) also showed alterations in routine and sleep in Italian children aged 6 to 14 in a self-reported study conducted through video-calls. Communication with relatives/friends outside the household was mainly sustained on a digital level, which increases screen time, but may be beneficial in lockdown circumstances. Regarding daily activities, we observed commonly found gender and agerelated differences (18): older children were less active than younger children and spent more time with screens, and boys spent more time playing screen games (34). Sedentary behaviors ( $<30$ min of physical activity, more than $2 \mathrm{~h}$ playing screen games and/or watching videos and/or TV) were observed in more than $35 \%$ of the children. The high rate of sedentary behaviors is in line with the above referred Spanish and Canadian studies $(17,18)$ that reported decreased physical activity and increased screen exposure during pandemic lockdown. Interestingly, a study performed in 2014 found that $24.5 \%$ of Argentinean children between 5 and 10 years-old did not meet the international requirements of physical activity and showed a sedentary behavior in front of screen (35). Therefore, the proportion of sedentary children during the COVID-19 outbreak was increased in Argentina, exacerbated by a decline in outdoor time. Spending time outdoors has already been associated with more physical activity, less sedentary time and improved sleep (18). Thus, children should be encouraged to play and be active, engaging in activities compatible with lockdown measures, to minimize the negative consequences of lockdown. 
The COVID-19 crisis has particularly affected vulnerable populations, including families with young children, who face dual caregiver and/or breadwinner demands (21) in a context of increasing poverty rate in Argentina. Although emotional state, lifestyle and activities of the children during lockdown did not depend on the SES, parents with lower SES were more worried about their health and economic issues (income, food/essential items), and these worries were also evident in their children. These findings indicate that 2 months of lockdown have an unfavorable impact on the emotional well-being mostly of vulnerable families, in line with reports from other authors (21).

Our study also aimed to identify factors that helped to support children's well-being. The key features for children's well-being unmasked by the current study were keeping a routine, a positive attitude from the parents and having a balcony/garden. The latter favors outdoor time and sleep, but does not increase physical activity. Keeping a routine similar to how things were before COVID-19 improves sleep, emotional state and dedication to school homework. These results agree with other authors who reported that mood state is more strongly related to life changes than specific COVID worries (36). Being an older parent and part-time working also favor dedication to school homework, and parents with positive attitudes such as playing with their children or helping them with school homework have a favorable impact on their emotional state. On the other hand, parents feeling lonely negatively affect the child's emotional state and sleep quality, and parents who feel worried or afraid highly condition the children's fears and worries, especially about shortage of food and money. Other authors reported that the parents' difficulty to deal with lockdown is associated with parent's stress, which impacts on children's behavioral and emotional problems (30), and distress levels are also mediated by child's behavioral and emotional difficulties (10). This is in line with our findings that parents feel stressed to keep children entertained and do not find time to play with them, though spending a lot of time in the house. Our results and results from other authors (21, 30) highlight the strong links between parental psychological well-being and the well-being of their children. When children do not have a predictable routine and do not have emotional support from their parents, they may show distress evidenced by emotional and behavioral problems.

It was recently reported that school closure due to COVID19 has adverse consequences on children's physical and mental well-being (37), and similar disruptions are evident in our study. School closure isolates and socially deprives children from contact with their peers and teachers and is an important element in routine changes. School closure also plays a key role in the increase of sedentary behaviors since schools, and particularly physical education classes, provide an adequate environment to promote active behaviors among children and adolescents (17). Finally, parents are left alone dealing with children's education and having children at home $24 \mathrm{~h} / 7 \mathrm{~d}$, while also have to manage home-working and childcare (30). Therefore, the relevance of school closure on children's well-being should be taken into account when adopting preventive COVID-19 measures.

One of the strengths of our study lies in the fact that it was conducted 2 months after the beginning of the lockdown measurements, a very critical moment of the pandemic in Argentina. However, some features of the present study should be considered. First, this is a cross-sectional correlational study, therefore we cannot reach a conclusion about the long-term impact of lockdown or determine a causal relationship between the variables studied, a longitudinal analysis of the effects of lockdown on children and their parents over time would help to better understand the long-lasting consequences of lockdown. Moreover, the answers of the survey were exclusively provided by the parents. This data collection method may provide less information than child reports or direct evaluation by experts. However, it should be kept in mind that self-reports are not adequate for young children and pandemic restrictions limits direct evaluation by experts. Despite these limitations, this study is the first to provide data on the repercussions of COVID-19 lockdown on Argentinean children.

In conclusion, current results show that 2 months of pandemic lockdown in Argentina affected emotional state and lifestyle of children and their parents. During the COVID-19 crisis, strong links between parental psychological status and the well-being of children were observed. Lockdown especially affected the emotional well-being of more vulnerable families. Although the impact of the pandemic lockdown seems inevitable, our results show the importance of keeping a consistent routine during school closure, with enough opportunities to play, read, rest, and engage in physical activity, trying to avoid spending too much time in front of a screen. Besides, support for parents who are facing a stressful experience should also be provided. Our findings can guide efforts to preserve and promote child well-being during lockdown, helping governments to decide the confinement rules to apply to children, especially regarding school closing. Confinement rules should be accompanied by recommendations and guidelines for parents and caregivers to help children (and adults) to cope with the COVID-19 crisis.

\section{DATA AVAILABILITY STATEMENT}

The raw data supporting the conclusions of this article will be made available by the authors, without undue reservation.

\section{ETHICS STATEMENT}

The studies involving human participants were reviewed and approved by Institutional Committee for the Revision of Research Protocols (CIRPI) of the Institute of Development and Paediatric Research (IDIP), La Plata Children's Hospital. The patients/participants provided their written informed consent to participate in this study.

\section{AUTHOR CONTRIBUTIONS}

MFA, MF, and MP designed the study and wrote the manuscript. MF, MP, MÁA, AA, MS, and MFA collected, analyzed, and interpreted the data. MF performed the statistical analysis. All authors approved the submitted versions. 


\section{FUNDING}

This work was supported by grants from Fondo para la Investigación Científica y Tecnológica (FONCyT) and Gran Logia de la Argentina (PICTO2017-0086), from Fundación Alberto Roemmers and from Fundación Florencio Fiorini to MFA.

\section{ACKNOWLEDGMENTS}

We thank the participants for their contribution to the study. We are grateful to Dr. Mario Perello for the supportive comments and careful reading of the manuscript and all the staff of the institute for their help in the dissemination of the survey.

\section{REFERENCES}

1. Hale T, Angrist N, Cameron-Blake E, Hallas L, Kira B, Majumdar S, et al. Oxford COVID-19 Government Response Tracker. Blavatnik School of Government (2020).

2. Novotny JS, Gonzalez-Rivas JP, Kunzova S, Skladana M, Pospisilova A, Polcrova A, et al. Risk factors underlying COVID-19 lockdowninduced mental distress. Front Psychiatry. (2020) 11:603014. doi: 10.3389/fpsyt.2020.603014

3. Canet-Juric L, Andres ML, Del Valle M, Lopez-Morales H, Poo F, Galli JI, et al. A longitudinal study on the emotional impact cause by the COVID-19 pandemic quarantine on general population. Front Psychol. (2020) 11:2431. doi: 10.3389/fpsyg.2020.565688

4. Di Renzo L, Gualtieri P, Cinelli G, Bigioni G, Soldati L, Attina A, et al. Psychological aspects and eating habits during COVID-19 home confinement: results of EHLC-COVID-19 Italian online survey. Nutrients. (2020) 12:2152. doi: $10.3390 /$ nu12072152

5. Gullo S, Misici I, Teti A, Liuzzi M, Chiara E. Going through the lockdown: a longitudinal study on the psychological consequences of the coronavirus pandemic. Res Psychother. (2020) 23:494. doi: 10.4081/ripppo.2020.494

6. Roma P, Monaro M, Colasanti M, Ricci E, Biondi S, Di Domenico A, et al. A 2month follow-up study of psychological distress among Italian people during the COVID-19 Lockdown. Int J Environ Res Public Health. (2020) 17:8180. doi: 10.3390/ijerph17218180

7. Gierc M, Riazi NA, Fagan MJ, Di Sebastiano KM, Kandola M, Priebe CS, et al. Strange days: adult physical activity and mental health in the first two months of the COVID-19 pandemic. Front Public Health. (2021) 9:325. doi: 10.3389/fpubh.2021.567552

8. Di Renzo L, Gualtieri P, Pivari F, Soldati L, Attina A, Cinelli G, et al. Eating habits and lifestyle changes during COVID-19 lockdown: an Italian survey. $J$ Transl Med. (2020) 18:229. doi: 10.1186/s12967-020-02399-5

9. Fontanesi L, Marchetti D, Mazza C, Di Giandomenico S, Roma P, Verrocchio MC. The effect of the COVID-19 lockdown on parents: a call to adopt urgent measures. Psychol Trauma. (2020) 12:S79-81. doi: 10.1037/tra00 00672

10. Mazza C, Ricci E, Marchetti D, Fontanesi L, Di Giandomenico S, Verrocchio $\mathrm{MC}$, et al. How personality relates to distress in parents during the Covid-19 lockdown: the mediating role of child's emotional and behavioral difficulties and the moderating effect of living with other people. Int J Environ Res Public Health. (2020) 17:6236. doi: 10.3390/ijerph17176236

11. Chen F, Zheng D, Liu J, Gong Y, Guan Z, Lou D. Depression and anxiety among adolescents during COVID-19: a cross-sectional study. Brain Behav Immun. (2020) 88:36-8. doi: 10.1016/j.bbi.2020.05.061

12. Duan L, Shao X, Wang Y, Huang Y, Miao J, Yang X, et al. An investigation of mental health status of children and adolescents in china during the outbreak of COVID-19. J Affect Disord. (2020) 275:112-8. doi: $10.1016 /$ j.jad.2020.06.029

\section{SUPPLEMENTARY MATERIAL}

The Supplementary Material for this article can be found online at: https://www.frontiersin.org/articles/10.3389/fped. 2021.660033/full\#supplementary-material

Supplementary Figure 1 | Emotional state of children during lockdown. Percentage of children displaying different emotional states during lockdown according to parental report.

\section{Supplementary Table 1 | Survey.}

Supplementary Table 2 | Description of parent and child characteristics $(N=814)$.

Supplementary Table 3 | Parent's feelings and worries during lockdown [n (\%)].

13. Golberstein E, Wen H, Miller BF. Coronavirus disease 2019 (COVID-19) and mental health for children and adolescents. JAMA Pediatr. (2020) 174:819-20. doi: 10.1001/jamapediatrics.2020.1456

14. Liu JJ, Bao Y, Huang X, Shi J, Lu L. Mental health considerations for children quarantined because of COVID-19. Lancet Child Adolesc Health. (2020) 4:347-9. doi: 10.1016/S2352-4642(20)30096-1

15. Orgiles M, Morales A, Delvecchio E, Mazzeschi C, Espada JP. Immediate psychological effects of the COVID-19 quarantine in youth from Italy and Spain. Front Psychol. (2020) 11:2986. doi: 10.3389/fpsyg.2020.579038

16. Meherali S, Punjani N, Louie-Poon S, Abdul Rahim K, Das JK, Salam RA, et al. Mental health of children and adolescents amidst COVID-19 and past pandemics: a rapid systematic review. Int J Environ Res Public Health. (2021) 18:3432. doi: 10.3390/ijerph18073432

17. Lopez-Bueno R, Lopez-Sanchez GF, Casajus JA, Calatayud J, Gil-Salmeron A, Grabovac I, et al. Health-related behaviors among school-aged children and adolescents during the Spanish Covid-19 confinement. Front Pediatr. (2020) 8:573. doi: $10.3389 /$ fped.2020.00573

18. Moore SA, Faulkner G, Rhodes RE, Brussoni M, Chulak-Bozzer T, Ferguson LJ, et al. Impact of the COVID-19 virus outbreak on movement and play behaviours of Canadian children and youth: a national survey. Int J Behav Nutr Phys Act. (2020) 17:85. doi: 10.1186/s12966-020-00987-8

19. Pietrobelli A, Pecoraro L, Ferruzzi A, Heo M, Faith M, Zoller T, et al. Effects of COVID-19 lockdown on lifestyle behaviors in children with obesity living in Verona, Italy: a longitudinal study. Obesity. (2020) 28:1382-5. doi: 10.1002/oby.22861

20. Segre G, Campi R, Scarpellini F, Clavenna A, Zanetti M, Cartabia M, et al. Interviewing children: the impact of the COVID-19 quarantine on children's perceived psychological distress and changes in routine. BMC Pediatr. (2021) 21:231. doi: 10.1186/s12887-021-02704-1

21. Gassman-Pines A, Ananat EO, and Fitz-Henley J II. COVID-19 and parent-child psychological well-being. Pediatrics. (2020) 146:e202007294. doi: 10.1542/peds.2020-007294

22. Patrick SW, Henkhaus LE, Zickafoose JS, Lovell K, Halvorson A, Loch $\mathrm{S}$, et al. Well-being of parents and children during the COVID19 pandemic: a national survey. Pediatrics. (2020) 146:e2020016824. doi: 10.1542/peds.2020-016824

23. Paz J. Child Poverty and Inequality in Argentina. COVID-19 Effects. UNICEF (2020).

24. INDEC. Incidencia de la Pobreza y la Indigencia en 31 Aglomerados Urbanos. Primer Semestre de 2020 (2020).

25. Wang C, Pan R, Wan X, Tan Y, Xu L, Ho CS, et al. Immediate psychological responses and associated factors during the initial stage of the 2019 coronavirus disease (COVID-19) epidemic among the general population in China. Int J Environ Res Public Health. (2020) 17:1729. doi: 10.3390/ijerph17051729

26. Aguilar-Farias N, Toledo-Vargas M, Miranda-Marquez S, Cortinez-O’ryan A, Cristi-Montero C, Rodriguez-Rodriguez F, et al. Sociodemographic predictors 
of changes in physical activity, screen time, and sleep among toddlers and preschoolers in Chile during the COVID-19 pandemic. Int J Environ Res Public Health. (2020) 18:176. doi: 10.3390/ijerph18010176

27. Xie X, Xue Q, Zhou Y, Zhu K, Liu Q, Zhang J, et al. Mental health status among children in home confinement during the coronavirus disease 2019 outbreak in Hubei province, China. JAMA Pediatr. (2020) 174:898-900. doi: 10.1001/jamapediatrics.2020.1619

28. Zhang X, Zhu W, Kang S, Qiu L, Lu Z, Sun Y. Association between physical activity and mood states of children and adolescents in social isolation during the COVID-19 epidemic. Int J Environ Res Public Health. (2020) 17:7666. doi: 10.3390/ijerph17207666

29. Cui Y, Li F, Leckman JF, Guo L, Ke X, Liu J, et al. The prevalence of behavioral and emotional problems among Chinese school children and adolescents aged 6-16: a national survey. Eur Child Adolesc Psychiatry. (2021) 30:233-41. doi: 10.1007/s00787-020-01507-6

30. Spinelli M, Lionetti F, Pastore M, Fasolo M. Parents' stress and children's psychological problems in families facing the COVID-19 outbreak in Italy. Front Psychol. (2020) 11:1713. doi: 10.3389/fpsyg.2020. 01713

31. Benjamini $Y$, Hochberg Y. Controlling the false discovery rate: a practical and powerful approach to multiple testing. J R Stat Soc Ser B. (1995) 57:289-300. doi: 10.1111/j.2517-6161.1995.tb02031.x

32. Cohen J. A power primer. Psychol Bull. (1992) 112:155-9. doi: 10.1037/0033-2909.112.1.155

33. Adams EL, Smith D, Caccavale LJ, Bean MK. Parents are stressed! patterns of parent stress across COVID-19. Front Psychiatry. (2021) 12:300. doi: 10.3389/fpsyt.2021.626456
34. Leblanc AG, Broyles ST, Chaput JP, Leduc G, Boyer C, Borghese MM, et al. Correlates of objectively measured sedentary time and self-reported screen time in Canadian children. Int J Behav Nutr Phys Act. (2015) 12:38. doi: 10.1186/s12966-015-0197-1

35. Tuñon I, Laíño F. Insuficiente actividad física en la infancia: niños, niñas y adolescentes entre 5 y 17 años en la Argentina urbana. Buenos Aires: Observatorio de la Deuda Social Argentina, Barómetro de la Deuda Social de la Infancia, Universidad Católica Argentina (2014).

36. Nikolaidis A, Paksarian D, Alexander L, Derosa J, Dunn J, Nielson DM, et al. The Coronavirus Health and Impact Survey (CRISIS) reveals reproducible correlates of pandemic-related mood states across the Atlantic. Sci Rep. (2021) 11:8139. doi: 10.1038/s41598-021-87270-3

37. Hoffman JA, Miller EA. Addressing the consequences of school closure due to COVID-19 on children's physical and mental well-being. World Med Health Policy. (2020) 12:300-10. doi: 10.1002/wmh3.365

Conflict of Interest: The authors declare that the research was conducted in the absence of any commercial or financial relationships that could be construed as a potential conflict of interest.

Copyright (๑) 2021 Fasano, Padula, Azrak, Avico, Sala and Andreoli. This is an open-access article distributed under the terms of the Creative Commons Attribution License (CC BY). The use, distribution or reproduction in other forums is permitted, provided the original author(s) and the copyright owner(s) are credited and that the original publication in this journal is cited, in accordance with accepted academic practice. No use, distribution or reproduction is permitted which does not comply with these terms. 